\title{
Light and electron microscopy of rabbit testes infected with Treponema pallidum (Nichols strain): nature of deposited mucopolysaccharides and localisation of
} treponemes

\author{
J J VAN der SLUiS, * F J W TEn KATE, $\dagger$ V D VUZEVSKI, $\dagger$ E STOLZ* \\ From the Departments of ${ }^{*}$ Dermatovenereology and $†$ Clinical Pathology, Erasmus University, Rotterdam, the \\ Netherlands
}

SUMMARY The mucopolysaccharide nature of the material deposited in rabbit testes infected with Treponema pallidum was confirmed by histochemical staining with alcian blue. Differential staining of mucopolysaccharides showed the presence of sulphated mucopolysaccharides as an almost constant feature, whereas in little more than half of the orchitic testes studied variable deposits of hyaluronic acid were seen. The treponemes were almost exclusively present in the areas rich in mucopolysaccharide. A combination staining with the Warthin-Starry method and alcian blue showed treponemes in close association with pre-existing fibrils and cells contained in these fibrils. The latter findings were confirmed by electron microscopy, and the fibroblasts to which treponemes adhered displayed the characteristics of activated cells. The close parallel between the histopathological changes observed here and their descriptions in published reports shows that our specific strain still behaves the same as the original Nichols pathogenic strain of $T$ pallidum.

In the course of syphilitic orchitis in rabbits three sequential but commonly overlapping phases can be distinguished: the inductive, the reactive, and the latent phases. ${ }^{12}$ During the inductive phase the number of treponemes increases and a loosely woven, acellular, amorphous substance forms, which seems to be deposited between the pre-existing testicular tissues. The presence of mucopolysaccharides in these areas was likely because of metachromatic staining with methylene blue and related stains. Scott and Dammin provided evidence that these changes were specific for the syphilitic process. ${ }^{3}$ The influx of large numbers of mononuclear cells marks the transition from the inductive to the reactive phase. The latent stage is characterised by interstitial flbrosis, which is considered to be a repair mechanism.

Mucopolysaccharides may be of considerable importance in syphilitic infection, as they have been

\footnotetext{
Address for reprints: Dr J J van der Sluis, Department of Dermatovenereology, Erasmus University, PO Box 1738, 3000 DR, Rotterdam, the Netherlands
}

Accepted for publication 25 January 1987 implicated as part of a protective cover of the treponemes. Zeigler et al showed that treponemes in vivo are surrounded by a ruthenium red stainable substance, ${ }^{4}$ which probably consists of mucopolysaccharides or closely related compounds. In vitro, the co-cultivation of pathogenic treponemes and various types of cultured cells resulted in the adherence of treponemes to these cells. ${ }^{56}$ Some authors consider that this adherence enhances the establishment of infection in a host. Fitzgerald et al have shown that co-cultivation resulted in cells covered with an amorphous layer of ruthenium red stainable material. ${ }^{7} \mathrm{~A}$ similar interaction between the host cells and treponemes in vivo could lead to the production of mucopolysaccharides. This appears to require close contact between treponemes and host cells.

This prompted us to study the nature of the mucopolysaccharides and the localisation of the treponemes in relation to host tissue components as a part of the histopathological changes produced by the Nichols pathogenic strain of Treponema pallidum. This strain has been used in our laboratory for several years. 


\section{Materials and methods}

The testes studied were obtained from 70 rabbits that had been used in a previous investigation to measure the in vitro survival time of $T$ pallidum in artificially infected stored donor blood. ${ }^{8}$ Orchitis developed in 39 rabbits. In 29 of them the diffuse type of orchitis was observed, the testes of the remaining 10 animals showed the nodular type of orchitis. In 31 animals neither orchitis nor serological evidence of infection was detected. Rabbits with the diffuse type of orchitis were killed at peak orchitis. Those with the nodular type were killed when firm nodules could be palpated. Rabbits without orchitis were killed after observation for four and a half months, and their testes served as controls.

The testes were removed and parts were fixed for light microscopy, histochemical studies, and electron microscopy. For light microscopy the testicular tissue was fixed in phosphate buffered $4 \%$ formaldehyde solution $(\mathrm{pH}=7.4)$ and embedded in Paramat (Gurr). Routine staining of $4 \mu \mathrm{m}$ thick tissue sections was performed with haematoxylin-azophloxin. Muco-polysaccharide specific staining was performed with alcian blue $8 \mathrm{GX}$ (Aldrich), according to Cook $^{9}$ at $\mathrm{pH}=2 \cdot 5$, using the neutral red modification. Carboxylated and sulphated mucopolysaccharides were differentially stained with the high iron diamine/alcian blue (HIDAB) method..$^{10}$ Hyaluronidase treatment of sections was performed with bull testicular hyaluronidase (Hyason, Organon, Oss, the Netherlands). Sections were incubated for one hour at room temperature in a solution containing $150 \mathrm{IU}$ hyaluronidase in $0.15 \mathrm{~mol} / 1$ sodium chloride. Treponemes were detected using the Warthin-Starry ${ }^{11}$ and Steiner ${ }^{12}$ staining methods. Satisfactory visualisation of the treponemes in connection with host tissue constituents was produced by the Warthin-Starry method, followed by staining with alcian blue as described above.

For electron microscopy small fragments of testicular tissue were fixed in a $4: 1$ mixture of $40 \%$ formaldehyde and glutaraldehyde, and were postfixed with $1 \%(\mathrm{w} / \mathrm{v})$ osmium tetroxide before acetone dehydration. The specimens were embedded in LX 112 (Epon). Semithin plastic sections for light microscopy were stained with a freshly prepared $1 \%$ toluidine blue solution in distilled water. Ultrathin sections

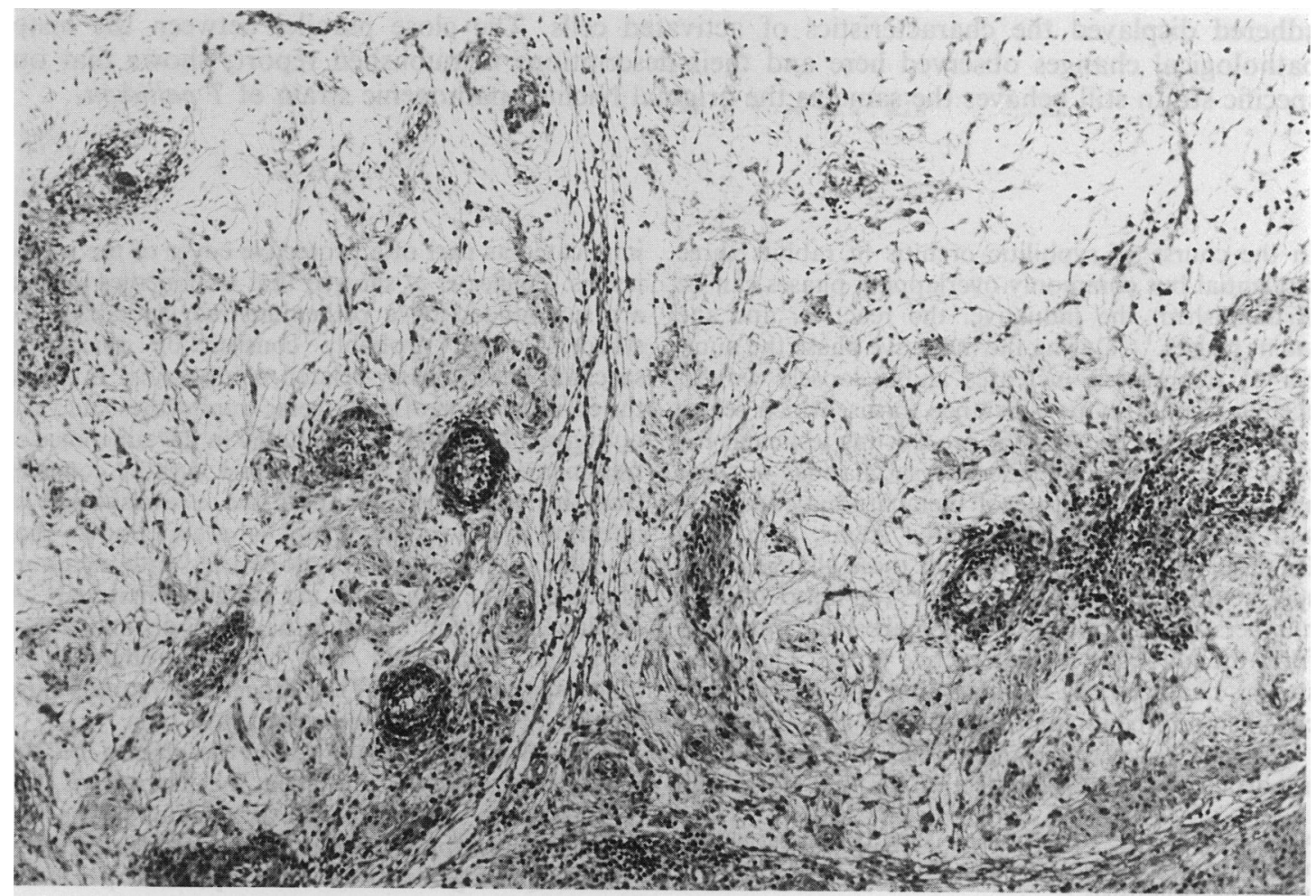

Fig 1 Section of rabbit testis infected with Treponema pallidum showing optically empty cell- poor areas with vasculitis (hematoxilin-azophloxin). 

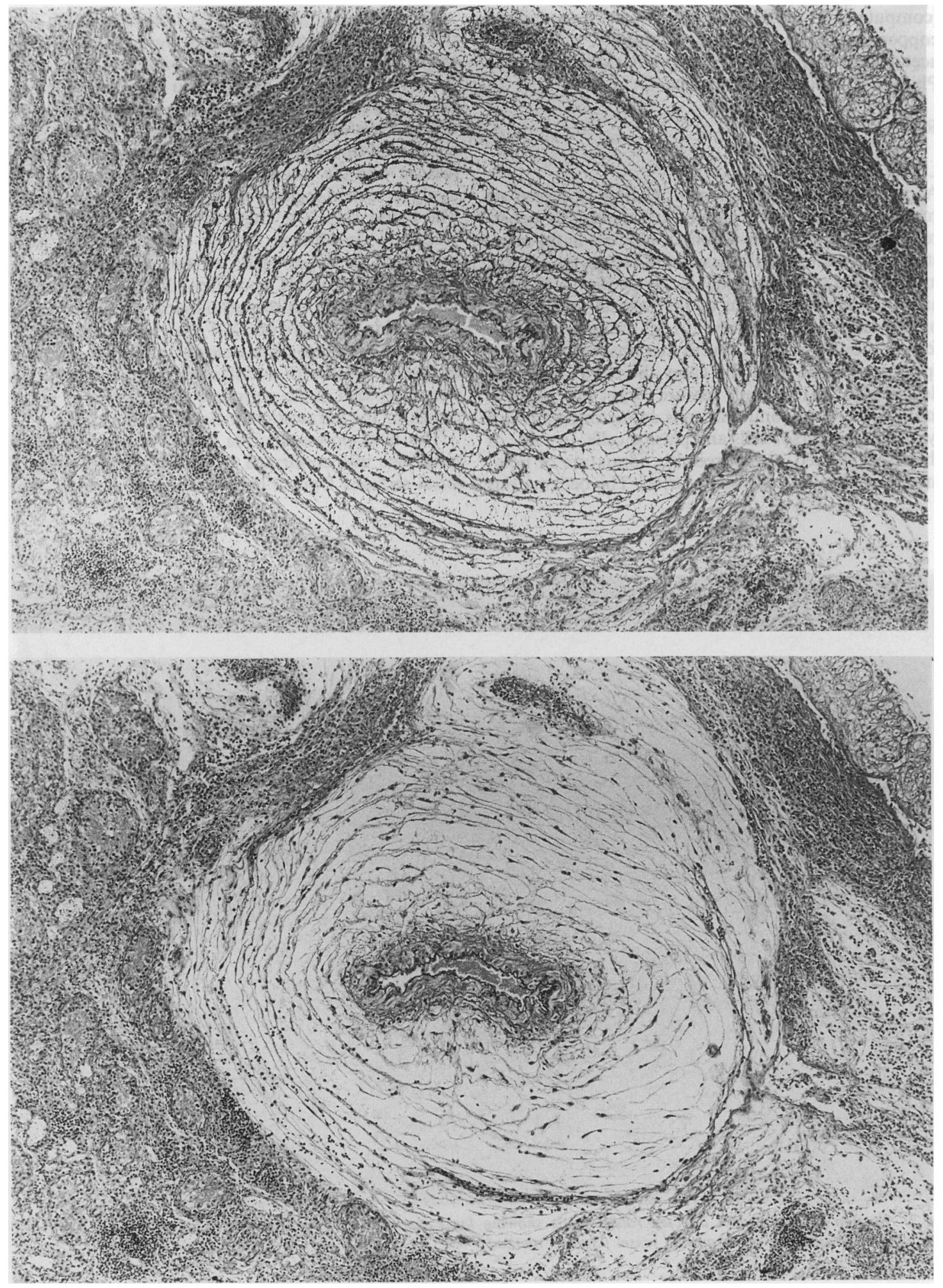

Fig 2 High iron diamine/alcian blue (HIDAB) stained sequential sections of T pallidum infected rabbit testis showing large vessel with perivascular cell poor area and accumulation of mucopolysaccharide like material before (upper) and after (lower) hyaluronidase treatment. 
(computerised LKB ultratome) were mounted on copper grids ( 300 mesh) and contrasted with uranyl acetate and lead citrate. ${ }^{13}$ They were examined with a Philips 201 electron microscope.

\section{Results}

\section{LIGHT MICROSCOPY}

A prominent histopathological change observed on routine staining of all orchitic testes was the occurrence of large cell poor oedematous areas in the interstitium of the testicular tissue and also often present in the tunica and paratesticular tissue (fig 1). In these areas serious destruction of the normal architecture of the testes had occurred. In all cases the seminiferous tubules showed severe atrophy with reduced spermatogenesis. In some cases there was complete destruction. A second feature was the massive infiltration of mononuclear cells consisting mainly of lymphoid precursor cells and plasma cells. In some of the testes studied, an appreciable admixture of polymorphonucleated cells was noticed. The oedematous areas were essentially free of the infiltrate, which gave the impression that these areas were surrounded by the infiltrate. Around the blood vessels in these areas the myxoid substance appeared to be arranged in concentric layers. Swelling and proliferation of the endothelial cells was observed in these vessels, with occasional thrombus formation in the lumen. A third feature was the interstitial fibrosis that could most easily be seen in regions not obscured by the infiltrate. The blood vessels in these areas showed prominent vasculitis. In diffuse orchitis these findings were extended to large parts of the testicular tissue, affecting at least half, and often all, the testicular tissue. The same histopathological changes were observed in restricted areas of otherwise normal looking testicular tissue from testes with nodular orchitis. In several testes with nodular orchitis the aberrations were only seen at the periphery of the testes or in the tunica or the paratesticular tissue, or both.

The mucopolysaccharide nature of the mucinous substance was confirmed by alcian blue staining of serial sections from a limited number of testes that

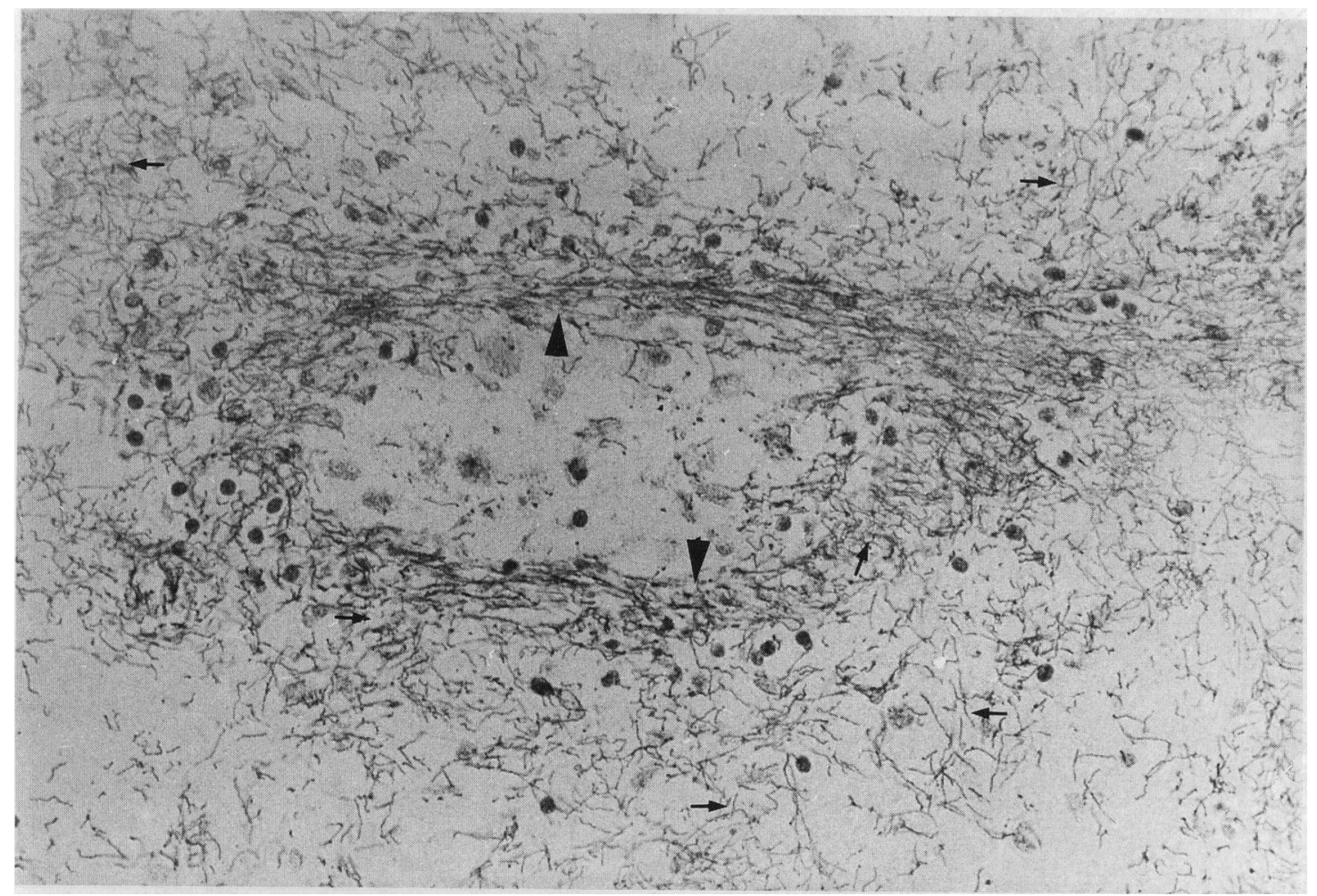

Fig 3 Section of $T$ pallidum infected rabbit testis showing large numbers of treponemes $(\rightarrow)$ in vessel wall ( $\rightarrow$ ) and mucopolysaccharide rich areas around vessel (Steiner method). 
were pretreated alternately with or without hyaluronidase. The blue staining, which was present in untreated sections, was completely absent in hyaluronidase treated sections. Similar results were obtained with HIDAB staining of similarly treated sections (fig 2, $a$ and $b$ ).

The differentiation of the deposited material in carboxylated or sulphated, or both, mucopolysaccharides by HIDAB staining was performed on the testes of the 70 rabbits. Positive staining was only observed in the oedematous areas of testicular tissue of rabbits with orchitis. In 33 rabbits black granular staining was seen, which appeared to be arranged in fibrillar patterns; in 14 rabbits this was the only staining. It was striking that apparently empty spaces were present between these fibrils (fig 2). In 19 rabbits the black fibrillar staining was accompanied by blue stained areas of various size and intensity of staining. In five rabbits only blue staining was observed. In the testes of one orchitic rabbit the HIDAB staining failed to show any mucopolysaccharide. The black fibrillar staining was again present in concentric layers around the blood vessels. Unaffected parts of these testes did not stain with the HIDAB stain. The testes of the 31 rabbits without orchitis were negative when stained with the mucopolysaccharide stains.

Treponemes, as revealed with the Warthin-Starry or Steiner staining methods, were shown in all testes that had clinical orchitis. When the Steiner method was used, large numbers of treponemes were detected. The impression that these organisms were preferentially present in the oedematous areas, especially around blood vessels (fig 3 ) was studied on serial sections, which were alternatively stained with the HIDAB and Warthin-Starry stains. Most of the treponemes were present in the oedematous areas. Outside these areas each section showed only a few treponemes. The presence of treponemes among the cells of the infiltrate could not be established with certainty because the infiltrate was very dense. The relation between the tissue components and the treponemes in the oedematous areas was studied in greater detail using the Warthin-Starry method, followed by alcian blue staining. Dark brown treponemes were

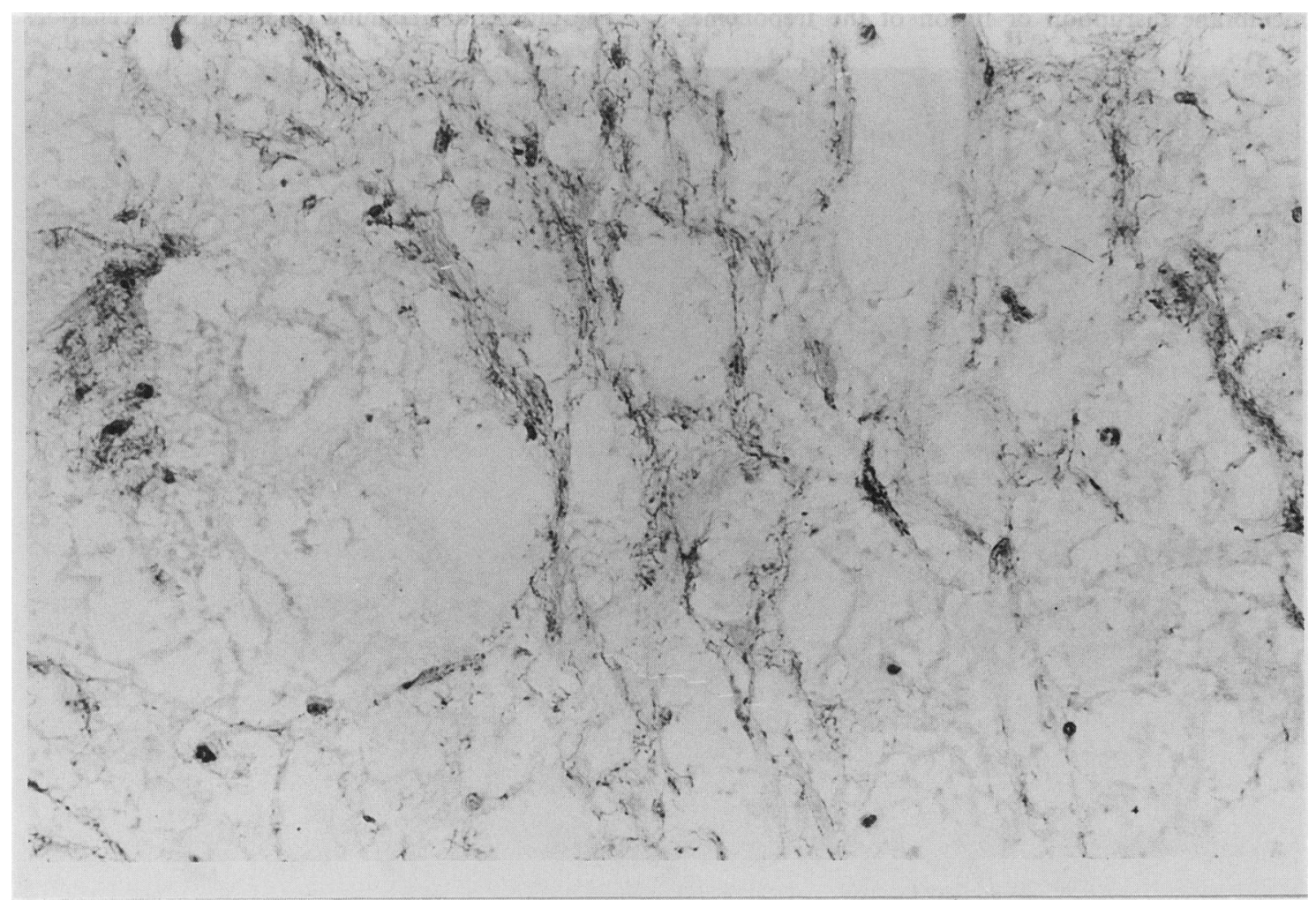

Fig 4 Low power magnification showing non-random distribution of treponemes in oedamatous tissue area, with treponemes localised in close association with tissue components. Note acellular amorphous areas between dark coloured fibrillar structures and absence of treponemes in these areas (Warthin-Starry followed by alcian blue). 
observed in an apparently close association with fibrillar structures and several treponemes adhered to the fibrils. Moreover, a close association was observed between treponemes and fibroblast like cells incorporated in these fibrils (figs 4 and 5).

\section{ELECTRON MICROSCOPY}

The metachromasia of toluidine blue stained semithin sections appeared to be very useful in the selection of areas containing treponemes. The "density" of treponemes in thin sections correlated positively with the presence of metachromasia in semithin sections. Many treponemes were found in the oedematous interstitial spaces of the testes (fig 6) and extracellularly in the walls of the capillary blood vessels. In the oedematous areas the treponemes were in close contact with mononuclear cells, mostly fibroblasts. At these places the cell membranes of the fibroblasts were less visible owing to possible deposition of material. The cells affected were enlarged and showed increased cytoplasmic contents, namely rough endoplasmic reticulum and Golgi apparatus. Less commonly the treponemes penetrated into cellular invaginations creating gaps without evidence of membrane disruption or fusion of the treponemes with the cellular membrane. Here the continuity of the cellular membrane was clearly preserved and could be observed by electron microscopy (fig 7).

\section{Discussion}

The histopathological changes observed in this study on routine staining of infected testicular tissue appeared to be a mixture of the changes present in the inductive, reactive, and latent phases of orchitis. ${ }^{2}$ These changes have been described as occurring simultaneously during orchitis. ${ }^{1}$ The positive alcian blue and HIDAB staining and their inhibition by hyaluronidase agree with earlier findings regarding the mucopolysaccharide nature of the interstitially deposited material. ${ }^{13}$ The Nichols pathogenic strain of $T$ pallidum used in the present experiments was obtained in 1975 from Dr J N Miller (UCLA, Los Angeles, California, USA) and has since then been propagated in rabbit testes. The histopathological and histochemical findings shown here are identical to those described previously. ${ }^{1-3}$ This shows that our specific strain of $T$ pallidum still behaves the same as the pathogenic Nichols strain.

The differential staining of mucopolysaccharides

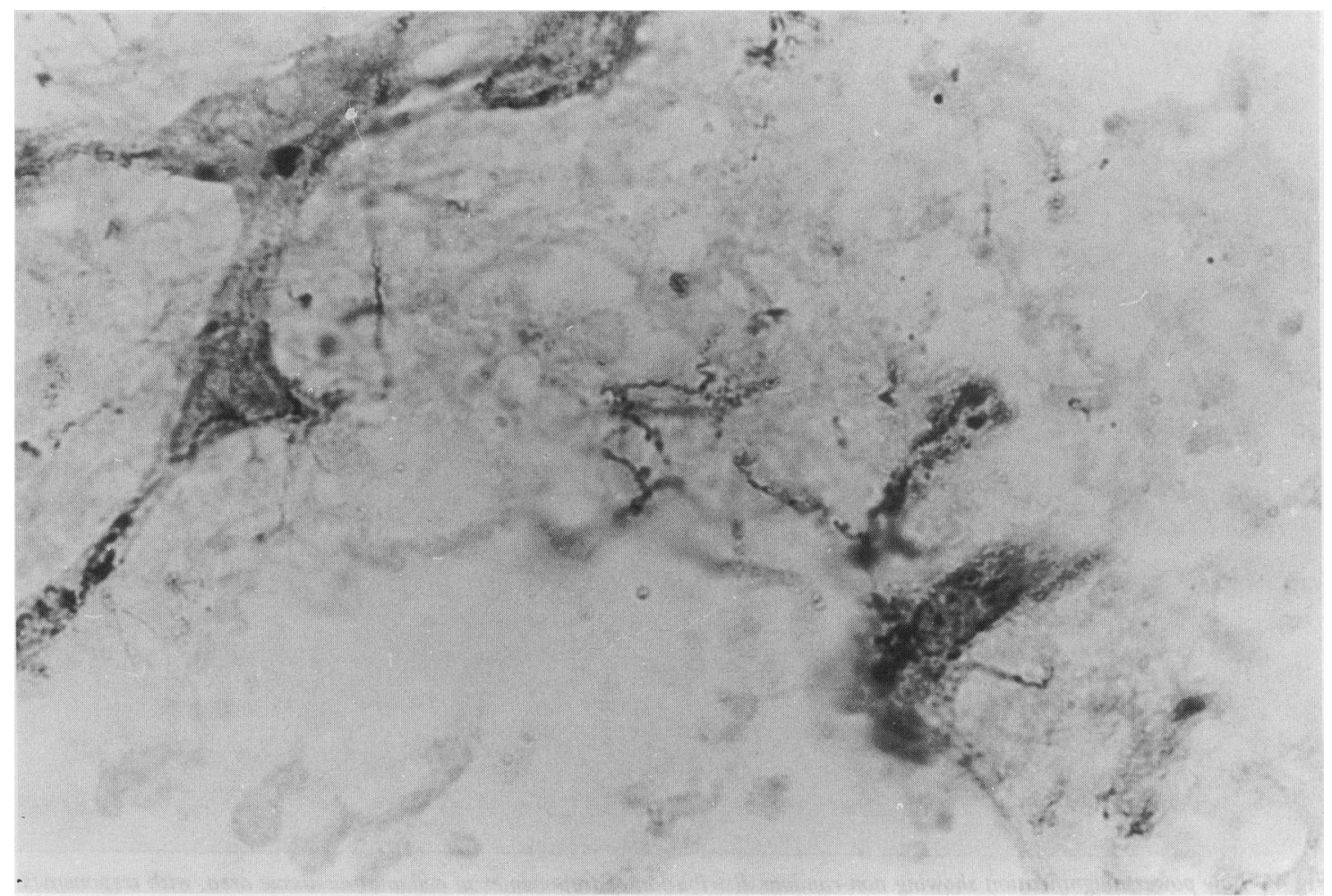

Fig 5 Larger magnification of section shown in fig 4, showing close association between treponemes and tissue cells (WarthinStarry followed by alcian blue). 
with the HIDAB procedure indicated variations in the presence of carboxylated and sulphated mucopolysaccharides. The latter were seen in most testes (33 out of 39 orchitic testes). Blue staining indicating the presence of hyaluronic acid was absent in 14 of these rabbits, whereas in 24 rabbits staining of variable intensity was observed. We have previously shown that extracts of testes contained increasing amounts of hyaluronic acid after incrcasing duration of orchitis. ${ }^{14}$ Sulphated mucopolysaccharides were not detected in these extracts, which shows that hyaluronic acid can be isolated casily from infected testicular tissue. The variable presence of hyaluronic acid in the testicular tissue sections may be related to this casy extractability, as hyaluronic acid may have been lost from the tissue sections as a result of the manipulations during the fixing and staining procedures. The empty spaces between the black fibrils in HIDAB staincd sections suggests such a loss of material. Moreover, in sections showing both types of staining, the blue staining was aligned along the black stained fibrils. This reinforces the idea of an alternative way of incorporating hyaluronic acid and the sulphated types of mucopolysaccharides in infected testicular tissuc. The fibrillar staining pattern of the sulphated mucopolysacchrides and their resistance to extraction suggest that they are strongly anchored in the fibrillar structures of the testicular tissue. Hyaluronic acid seems to be loosely bound between these fibrils.

There is still no conclusive evidence about whether the treponemes or host tissue cells in the presence of treponemes are responsible for the production of mucopolysaccharides. Strugnell et al have shown that treponemes in vitro do not incorporate radiolabelled precursors into their mucopolysaccharides. ${ }^{15}$ Slices of the infected unilateral testes of intratesticularly infected rabbits, however, showed greater incorporation of radiolabelled mucopolysaccharide precursors $\left(\left[{ }^{35} \mathrm{~S}\right]\right.$ sulphate and $\left[{ }^{3} \mathrm{H}\right]$ glucosamine) than slices from non-infected contralateral testes. Penicillin treatment of these rabbits or slices of their testes effectively killed the treponemes, but incorporation of labelled substances remained higher in the infected than in the non-infected tissue. ${ }^{16}$ These authors concluded that the incorporation of radiolabelled precursors represented the biosynthesis of these macromolecules by the host and not by the treponemes, and that active syphilitic infection was necessary for the maximum biosynthesis of these macromolecules by the host tissue. Our findings concerning the close association of

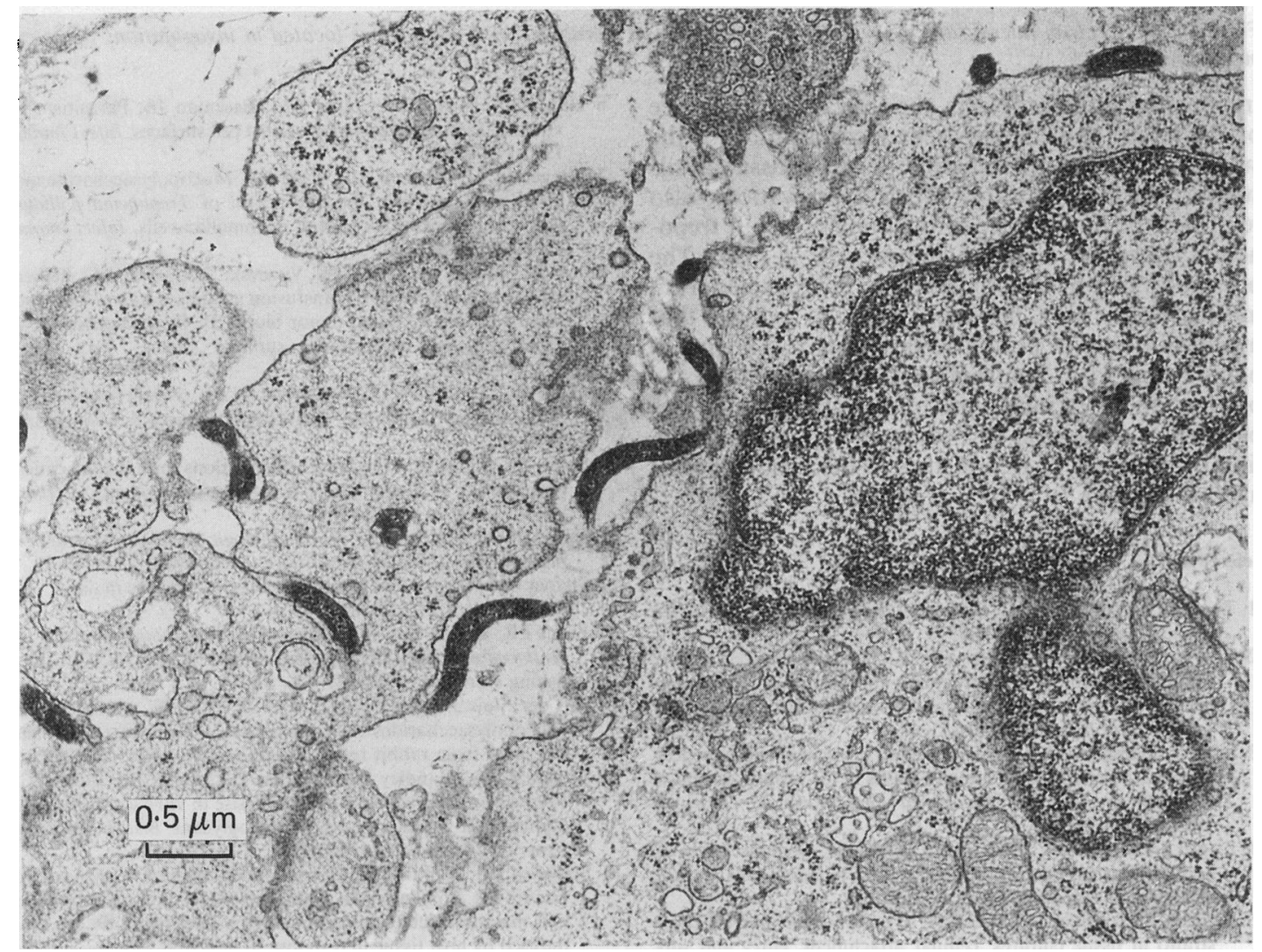

Fig 6 Photoelectron micrograph of area of infected testicular tissue containing large numbers of treponemes and metachromasia (toluidine blue) 


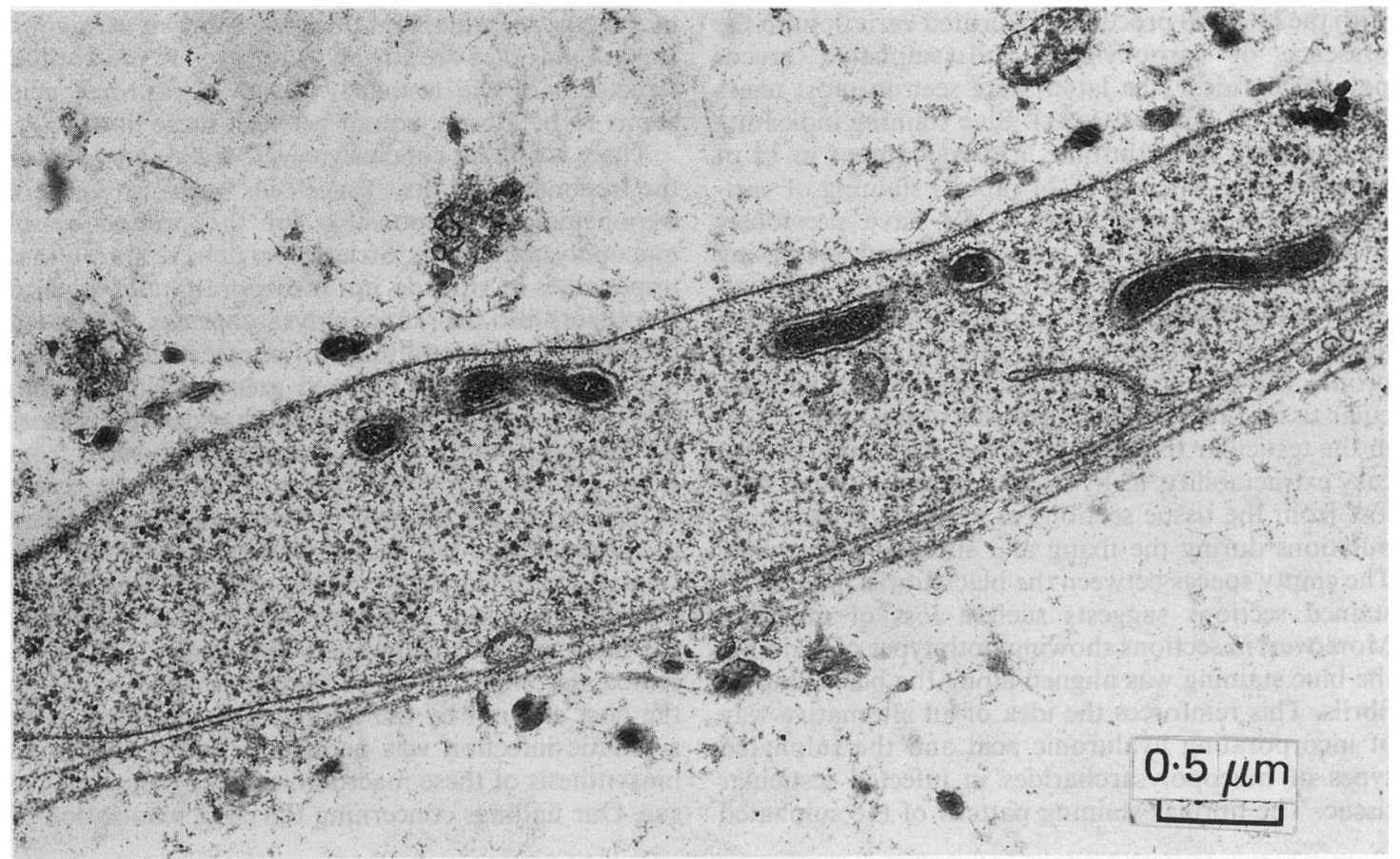

Fig 7 Photoelectron micrograph of cytoplasmic protrusion of fibroblast with treponemes located in invaginations of its cell membrane.

treponemes with fibroblasts, the activated appearance of the latter, and the apparent incorporation of the sulphated mucopolysaccharides into the tissue fibrils support their conclusion. These observations also reinforce the importance of the findings about treponemal adherence to tissue culture cells in vitro. The possibility that hyaluronic acid can be extracted from infected testes only, however, seems to indicate that hyaluronic acid is produced in excess. ${ }^{14}$ This could point either to a disturbance of homeostasis in the production of various types of mucopolysaccharides by the host tissue cells as a result of treponemal infection or to a role of treponemes in the production of hyaluronic acid.

\section{References}

1 Turner TB, Hollander DH. Biology of the treponematoses. $\mathrm{WHO}$ Monograph Series 1957;35:35-8.

2 Sell S, Baker-Zander S, Powell HC. Experimental syphilitic orchitis in rabbits. Ultrastructural appearance of Treponema pallidum during phagocytosis and dissolution by macrophages in vivo. Lab Invest 1982;46:355-64.

3 Scott V, Dammin GJ. Morphologic and histochemical sequences in syphilitic and in tuberculous orchitis in the rabbit. American Journal of Syphilis, Gonorrhea and Venereal Diseases 1954;38:189-202.

4 Zeigler JA, Jones AM, Jones RH, Kubica KM. Demonstration of extracellular material at the surface of $T$ pallidum cells. British Journal of Venereal Diseases 1976;52:1-8.

5 Fitzgerald TJ, Miller JN, Sykes JA. Treponema pallidum (Nichols strain) in tissue cultures: cellular attachment, entry and survival. Infect Immun 1975;11:1133-40.
6 Hayes NS, Muse KE, Collier AM, Baseman JB. Parasitism by virulent Treponema pallidum of host cell surfaces. Infect Immun 1977;17:174-86.

7 Fitzgerald TJ, Johnson RC, Wolff ET. Mucopolysaccharide material resulting from the interaction of Treponema pallidum (Nichols strain) with cultured mammalian cells. Infect Immun 1978:22:575-84.

8 van der Sluis JJ, ten Kate FJW, Vuzevski VD, Kothe FC, Aelbers GMN, van Eijk RVW. Transfusion syphilis, survival of Treponema pallidum in stored donor blood. II. Dose dependence of experimentally determined survival times. Vox Sang 1985;49:390-9.

9 Cook HC, In: Bancroft JD, Stevens A, eds. Theory and practice of histological techniques Edinburgh: Churchill Livingstone, 1977:152.

10 Spicer SS, Leppi TJ, Stoward PJ. Suggestions for a histochemical terminology of carbohydrate-rich tissue components. J Histochem Cytochem 1965;13:599-603.

11 Lillie RD, Fullmer HM. Histopathologic technic and practical histochemistry. 4th ed. New York: McGraw-Hill, 1976:761.

12 Steiner G. Modified silver stain for micro-organisms in tissue. $\mathrm{Am}$ $J$ Clin Pathol 1950;20:489-90.

13 Lewis PR, Knight DF. In: Glauert AM, ed. Staining methods for sectioned material. 3rd Ed. Amsterdam: North Holland Publishing Company, 1982: 47-55.

14 van der Sluis JJ, van Dijk G, Boer M, Stolz E, van Joost Th. Mucopolysaccharides in suspensions of Treponema pallidum extracted from rabbit testes. Genitourin Med 1985;61:7-12.

15 Strugnell RA, Handley CJ, Lowther DA, Faine S, Graves SR. Treponema pallidum does not synthesise in vitro a capsule containing glycosaminoglycans or proteoglycans. British Journal of Venereal Diseases 1984;60:8-13.

16 Strugnell RA, Handley CJ, Drummond L, Faine S, Lowther DA, Graves SR. Polyanions in syphilis: evidence that glycoproteins and macromolecules resembling glycosaminoglycans are synthesised by host tissue in response to infection with Treponema pallidum. British Journal of Venereal Diseases 1984;60:75-82. 